\title{
Poor versus good sleepers in patients under treatment for sleep-related breathing disorders: better is not good enough
}

This article was published in the following Dove Press journal:

Neuropsychiatric Disease and Treatment

17 January 2014

Number of times this article has been viewed

\author{
Christian Veauthier ${ }^{1,2}$ \\ 'Hanse-Klinikum, Department \\ of Neurology, Stralsund, Germany; \\ ${ }^{2}$ Department of Neurology, Centre \\ Hospitalier de Belfort-Montbéliard \\ (CHBM), Montbéliard, France
}

Correspondence: Christian Veauthier Centre Hospitalier de BelfortMontbéliard (CHBM), Department of Neurology, 2 rue du Dr Flamand, 252II Montbéliard, France Tel +33680756030

Fax +4932I 2828668

Email cveauthier@web.de

\section{Dear editor}

Recently we published a retrospective study in this journal which reported the significant relationship between nocturnal awakening, respectively high arousal index, and fatigue in 410 patients with sleep disorders admitted to our sleep laboratory. ${ }^{1}$

In this study we noticed that Pittsburgh Sleep Quality Index (PSQI) mean values ${ }^{2}$ were lower in patients who have been treated for sleep-related breathing disorders (SRBD) compared with either treatment-naïve SRBD patients, or with patients with periodic limb movement disorder (PLMD), restless legs syndrome (RLS), or insomnia. However, this study was not focused on PSQI values and we did not classify the patients into good and poor sleepers according to the established PSQI cut-off (less than or equal to versus greater than five). The PSQI was initially developed to screen impaired subjective sleep quality in patients with insomnia and depression, but today it is widely used in sleep medicine in general.

We now report the results of a classification of our patients into good and poor sleepers according to their PSQI values, using the PSQI-cut-off of $\leq$ or $>5$ that we performed subsequent to our original study.

To our knowledge, there have been to date only a few studies in this issue that have investigated the use of PSQI in obstructive sleep apnea (OSA) patients. These studies had inconsistent findings and small sample sizes.

Macey et $\mathrm{al}^{3}$ did not find a significant relationship between the apnea-hypopneaindex per hour of sleep (AHI) and PSQI values in 49 untreated OSA patients.

Chihara et $\mathrm{al}^{4}$ reported a significant improvement of PSQI values after auto-adjusting positive airway pressure (APAP) with flexible positive airway pressure (C-Flex) $(n=29)$, but not with APAP alone ( $\mathrm{n}=28)$ or APAP in combination with fixed inspiration/expiration pressure difference (A-Flex) $(\mathrm{n}=28)$.

Mermigkis et $\mathrm{al}^{5}$ found no significant improvement of PSQI values before and after continuous positive airway pressure (CPAP) in a small sample of 12 patients.

\section{Patients and methods}

From our original cohort of 410 patients who were admitted to the sleep laboratory of the Hanse-Klinikum Stralsund (Germany) between 1 February 2011 and 31 January 2012, we included untreated SBRD patients ( $\mathrm{n}=231 ; 176$ men and 55 women), treated SRBD patients $(\mathrm{n}=102 ; 80$ men and 22 women; treatment with APAP, CPAP and bi-level positive airway pressure [BiPAP] therapy), insomnia patients ( $n=22$; six men 
and 16 women) and RLS/PLMD patients $(n=19$; six men and 13 women). Due to small sample sizes, the patients with parasomnia, hypersomnia, narcolepsy, myasthenia, and those without proven sleep disorders were not included. For details (demographic parameters, results of performed polysomnographies and self-assessed scales) please see the original article. ${ }^{1}$

All patients in the different subgroups were divided in good sleepers (PSQI $\leq 5$ ) versus poor sleepers (PSQI $>5$ ). In the different subgroups we compared the polysomnographic (PSG) parameters between good and poor sleepers (AHI, minimal desaturation; sleep efficacy, deep sleep, number of awakenings; arousal index per hour of sleep; sleep latency). We used Fisher's exact test. The results were expressed as mean, $\mathrm{SD}$, and range. Statistical significance was established at $P<0.05$. Analysis was performed with SPSS software (v19; IBM Corporation, Armonk, NY, USA).

\section{Results}

Whereas all insomnia patients, the majority of RLS/PLMD patients $(91.7 \%)$, and most untreated SRBD patients $(72.0 \%)$ were poor sleepers, approximately half $(50.7 \%)$ of treated SRBD patients were poor sleepers.

When comparing the number of poor sleepers in the different subgroups with Fisher's exact test, there was a highly significant difference between treated SRBD patients and all other subgroups (with untreated SRBD $P=0.002$; with insomnia $P=0.002$; with RLS/PLMD $P=0.008$ ). The comparison of untreated SRBD patients with RLS/PLMD patients $(P=0.139)$ and with insomnia patients $(P=0.068)$ showed no significant difference.

As in insomnia patients, there was no one good sleeper, and we could not compare the PSG parameters between good and poor sleepers in this subgroup. The comparison of the PSG parameters in RLS/PLMD between good and poor sleepers showed no significant differences.

The comparison of the PSG parameters in the untreated SRBD subgroup (good versus poor sleepers) showed a significant difference regarding deep sleep, which was higher in good sleepers (mean 10.2\%, standard deviation [SD] 10.8; interquartile range [IQR] [25\%-75\%] 1.2\%-14.8\%) compared with poor sleepers (mean 7.2; SD 9.5; IQR [25\%-75\%] $0.5 \%-12.2 \%)(P=0.035)$. The comparison of all other PSG parameters did not show any significant difference.

In the treated SRBD subgroup, there were three PSG parameters significantly different in good versus poor sleepers: firstly, the good sleepers showed a lower AHI (mean 1.7; SD 5.6; IQR [25\%-75\%] 0.1-1.2) compared with poor sleepers (mean 5.0; SD 14.9; IQR [25\%-75\%]
0.5-2.4) ( $P=0.002)$. Moreover, the good sleepers showed a higher minimal desaturation (mean 90.2; SD 2.7; IQR [25\%-75\%] 88-92.8) compared with poor sleepers (mean 88.7 SD [25\%-75\%] 87-91) $(P=0.047)$ and the good sleepers showed a higher arousal-index (mean 21.7; SD 9.6; IQR [25\%-75\%] 14.5-24.9) compared with poor sleepers (mean 17.3; SD 8.0; IQR [25\%-75\%] 11.6\%-20.9\%) $(P=0.03)$. The other PSG parameter did not show any significant difference in this subgroup.

\section{Discussion}

This is, to our knowledge, the largest study of its kind investigating the PSQI values in patients with treated and untreated SRBD resulting in some interesting findings.

Firstly, it shows clearly that in treated SRBD patients there are more good sleepers than in untreated SRBD patients or in patients admitted to the sleep laboratory with insomnia, RLS, and PLMD.

Secondly, in treated SRBD patients who are good sleepers, the respiratory parameters (AHI, lowest oxygen desaturation) are less impaired compared with those who are poor sleepers.

Nevertheless, half of treated SRBD patients still remain poor sleepers, which may be important in the setting of CPAP resistant syndrome (residual sleepiness and/or fatigue, reduced quality of life), which occurs in approximately $10 \%$ of CPAP treated patients. ${ }^{6}$

The fact that in untreated SRBD patients, good sleepers show more deep sleep compared with poor sleepers does not need any explanation. However, we are not able to account for the higher arousal-index in the treated, good sleeper SRBD patients compared with the poor sleepers in the same subgroup.

Our study has some methodical limitations: the retrospective design and the fact that we did not investigate depression. Moreover, we did not investigate the same patients before and after CPAP.

\section{Conclusion}

Patients with CPAP or BiPAP therapy for SRBD were significantly less frequently poor sleepers compared with untreated SRBD patients, but at least half of them still remain poor sleepers. Good sleepers who were treated for SRBD showed significantly lower AHI compared with poor sleepers who are treated for SRBD.

\section{Acknowledgments}

The author thanks Dr Gosia Sullivan for reviewing this communication. 


\section{Disclosure}

The author declares no conflicts of interest in this communication.

\section{References}

1. Veauthier C. Younger age, female sex, and high number of awakenings and arousals predict fatigue in patients with sleep disorders: a retrospective polysomnographic observational study. Neuropsychiatr Dis Treat. 2013;9:1483-1494.

2. Buysse DJ, Reynolds CF 3rd, Monk TH, Berman SR, Kupfer DJ. The Pittsburgh Sleep Quality Index: a new instrument for psychiatric practice and research. Psychiatry Res. 1989;28(2):193-213.
3. Macey PM, Woo MA, Kumar R, Cross RL, Harper RM. Relationship between obstructive sleep apnea severity and sleep, depression and anxiety symptoms in newly-diagnosed patients. PLoS One. 2010;5(4): e10211.

4. Chihara Y, Tsuboi T, Hitomi T, et al. Flexible positive airway pressure improves treatment adherence compared with auto-adjusting PAP. Sleep. 2013;36(2):229-236.

5. Mermigkis C, Bouloukaki I, Antoniou KM, et al. CPAP therapy in patients with idiopathic pulmonary fibrosis and obstructive sleep apnea: does it offer a better quality of life and sleep? Sleep Breath. 2013;17(4): 1137-1143.

6. Launois SH, Tamisier R, Lévy P, Pépin JL. On treatment but still sleepy: cause and management of residual sleepiness in obstructive sleep apnea. Curr Opin Pulm Med. 2013;19(6):601-608.

\section{Publish your work in this journal}

Neuropsychiatric Disease and Treatment is an international, peerreviewed journal of clinical therapeutics and pharmacology focusing on concise rapid reporting of clinical or pre-clinical studies on a range of neuropsychiatric and neurological disorders. This journa is indexed on PubMed Central, the 'PsycINFO' database and CAS.
The manuscript management system is completely online and includes a very quick and fair peer-review system, which is all easy to use. Visit http://www.dovepress.com/testimonials.php to read real quotes from published authors.

Submit your manuscript here: http://www.dovepress.com/neuropsychiatric-disease-and-treatment-journal 